\title{
Communication Skills and its Impact on the Marketability of UKM Graduates
}

\author{
Ahmad Wazir Aiman Bin Mohd Abd Wahab ${ }^{1} \&$ Noor Akmal Shareela Binti Ismail ${ }^{1}$ \\ ${ }^{1}$ Biochemistry Department, Faculty of Medicine, Universiti Kebangsaan Malaysia Medical Center, Kuala Lumpur, \\ Malaysia \\ Correspondence: Noor Akmal Shareela Binti Ismail, Biochemistry Department, Faculty of Medicine, Universiti \\ Kebangsaan Malaysia, Jalan Yaacob Latif, 56000 Kuala Lumpur, Malaysia. E-mail: nasismail@ukm.edu.my
}

Received: September 2, 2014

Accepted: September 14, 2014

Online Published: September 16, 2014

doi:10.5430/ijhe.v3n4p64

URL: http://dx.doi.org/10.5430/ijhe.v3n4p64

\begin{abstract}
Organizations have always placed emphasis on the public's voices as an effort to continue enhancing their service towards society. University's performance and its relevance in a nation is highly dependent on the marketability of its students. The ability to widely distribute their students and to heighten their mobility in society and in the work field importantly reflects the overall performance of the University. The Universiti Kebangsaan Malaysia placed eight compulsory soft skills courses every student has to pass before they can graduate. This was done to ensure that all of Universiti Kebangsaan Malaysia's students are exposed with all dimensions of soft skills throughout their studies as they play a crucial role in enhancing students' marketability. Perceptions from 35 final year students, 2 lecturers, 3 Private Sector representative and 20 first year students towards the beneficial roles of these skills were conducted via interview. It's agreeable that communication skills are the most favorable to determine the marketability of UKM students. Low command of both Bahasa Melayu and English are one of the contributing factors to this. UKM graduates are seen to be less sensitive towards recent issues around the world thus they're not confident to participate in a group discussion. This article will reveal problems and strategic ways to encounter challenges, by enriching UKM students with different learning experiences of good communication skills and its impact towards their marketability after they graduate.
\end{abstract}

Keywords: Soft skills, Graduates marketability, Communication skills, Universiti Kebangsaan Malaysia

\section{Introduction}

Higher education is undeniably a very important factor in the process of developing a nation. In order to remain relevant to the ever-changing, ever-competing global market, many governments invest heavily in planning out careful strategies in the education sectors to generate value-added capabilities to the present and future human capital. Hence, the education sector is considered to play an important role in the process of national development and nation building (Kee et al., 2012). In the context of higher learning institutions, they need to make sure that the human capital they generate are able to function exceptionally well in society. This is significantly crucial as the capability, knowledge and skills of these students will represent to their institution. Failure to produce competent graduates will harshly damage the reputation or the image of the institution especially when it comes to the most renowned university in Malaysia. In Universiti Kebangsaan Malaysia (UKM), honored as one of the leading Research Universities (RU) in Malaysia, the task of making sure that their students are marketable and are able to bring themselves in the real world becomes even more solemn and serious. This is because RU are the standards of highly respected Universities that draws the benchmark not just for other local Universities to trail, but also for the distinction from other neighboring prestigious University such as the National University of Singapore. The picture that is being drawn under current situation illustrate that most of UKM students mobilize themselves effectively in both science and non-science organizations. Thus, the gravity that the university holds in terms of this sector allows the University to have greater funds or capital for research and development and possesses more influence in aspects of reliability and trustworthiness from international and local organization (Shaharuddin Ahmad et al., 2011). 


\section{Literature Review}

A good higher learning organization is perceived by the public to produce graduates as to increase manpower value for the work market (Kee et al. 2012). In this context, graduates are seen as a human capital as well as the key measurement of a university's effort in human resources development (Kee et al. 2012). However, getting a degree is not a gold ticket to get a job, thus the graduates must be well-equipped and challenge themselves in order to keep remain in the competition. A balance of hard skills and soft skills however, complement each other and associated to a job that is undertaken (Spencer \& Spencer 1993, Kemper 1999, McMuchie 1998). This is also believed that these skills are essential for a successful performance (Ashton 1994, Caudron 1999).

In Malaysia, there are 38 public and private universities who might produce graduates from a similar field; therefore there must be a strategy for each university to brand their graduates so their employability after graduation is secured. According to Malaysian Higher Education Ministry, all tertiary education institutes in Malaysia has produced 184, 581 graduates in 2011 but only 140,190 secured a job within 6 months of graduating. However, there is an immense competition between UKM graduates and the rival universities (Laporan Pengesanan Graduan IPT, 2011).

It was found that among the prestigious local universities UKM has the lowest percentage of graduates securing a job 6 months after graduating, which is at $68 \%$, falling far behind Universiti Sains Malaysia whose rate is $78 \%$ and Universiti Teknologi Petronas at 99\% (Laporan Pengesanan Graduan IPT, 2010). Furthermore, the percentage of UKM graduates securing a job within 6 months after graduating has declined from $62.21 \%$ to $50.56 \%$ from 2011 to 2012 (Laporan Kajian Pengesanan Graduan UKM, 2012). Despite having immense emphasis towards the overall development of soft skills, the UKM's graduate marketability is still not on par with rival universities in Malaysia. This is far less behind from Universiti Teknologi Petronas (UTP) where their employment after 6 month of graduation is 92\% in 2013 (Laporan Kajian Pengesanan Graduan UKM, 2013).

In respond of this trend, UKM has conducted a preliminary survey to see the quality of its graduates amongst the employers in Malaysia (UKM Students Development Centre, unpublished data). Most of the major companies (example, Petronas and Sime Darby) have made a common remark of young graduates from UKM. The similarity is, lacking in communication especially in English. This finding also shared by Ishak et al. (2008), Ismail et al. (2011) and Department of Statistic Report (Columnist, 2013), where the majority of the graduates lack of few soft skills corresponding to the job they applied, be it through communication skills and language proficiency.

To overcome this problem, further focus and emphasis is needed towards a particular, demanded skill so that UKM's graduate will have better foundation and establishment towards that skill and ultimately becomes an employer's material. One of them is by introducing the soft skills development curriculum. This can be done to promote all the necessary essence of marketability within UKM students, thus familiarizing them with the real world challenges and giving them the opportunity to be ahead of the competition. Prior to this, UKM places 8 compulsory soft skills courses for every one of its students to pass before they can graduate. This was done to ensure that all of UKM's students are exposed with all the 8 dimensions of soft skills throughout their studies as they play a crucial role in enhancing student's marketability. The 8 compulsory soft skills courses are:

1) Social skills \& Sense of responsibility,

2) Communication skills,

3) Information management \& Lifelong learning,

4) Values, attitudes, ethics \& professionalism,

5) Critical thinking,

6) Problem-solving \& Scientific approach,

7) Leadership \& Teamwork, Management \& Entrepreneurial skills,

8) Creative \& Innovative Skills.

Therefore, we aim to see which one of these soft skills is thought to be the most important in producing great graduates and enhance their marketability. We shall discuss in depth why these soft skills need to be acquired throughout University life prior to produce a marketable graduate. 


\section{Methodology}

\subsection{Research Design}

This is a qualitative research to determine the relationship of dependent and independent variables (Hopkins, 2000). It is designed to understand which of the variables that can be identified as a causal factors contributing to any changes. This study is aiming to see the correlation of 8 variables set by UKM that will correlate to the marketability of the graduates based on the research framework in Figure 1.

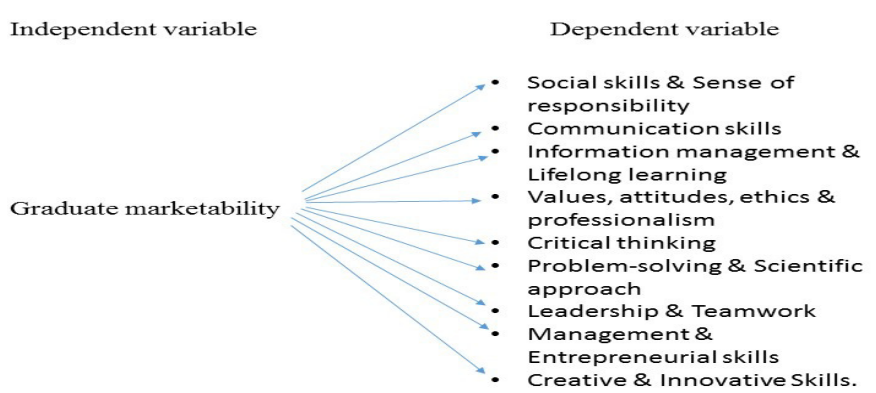

Figure 1. Research framework

The samples were randomly chosen from first year to final year undergraduates in Universiti Kebangsaan Malaysia. They came from various disciplines and involved three campuses, UKM Medical Centre, UKM Bangi, and UKM Kuala Lumpur Campus. We also conducted interviews with professionals who serve as lectures, directors and employers. When we were deciding on the sample number, we took an approach by Bertaux, 1981 who suggested that in all qualitative research, the smallest sample is acceptable as little as 15. As we were conducted the research, we have found that the response was quite similar and has reached saturation. While the distribution of mean sample is suggested as minimum as 31 (Mason, 2010), the existing data does not lead to any new information. Therefore, we only recruited 60 respondents for this study.

\subsection{Research Instrument}

The interview were conducted and based on a series of questions regarding the manifestation of each soft skill set by UKM as below. They were first asked what they know about certain soft skills (S1-8) involved in UKM curriculum and later followed up by their opinion in stressing which one is the most relevant in producing a good and marketable graduate.

\section{S1: Communication skills:}

- Ability to convey ideas clearly, effectively and confidently, orally and written

- Ability to practice active listening and give feedback

- Ability to give clear presentation confidently adjusting to the level of listeners

\section{S2: Critical thinking and problem-solving skills using scientific approach:}

- Ability to identify and analyse problems in complex and gray situation as well to make a justified evaluation

- Ability to expand and improve thinking skills such as explaining, analysing and evaluating discussions

- Ability to find ideas and alternative solutions

\section{S3: Leadership and Teamwork skills:}

- Knowledge regarding fundamental leadership theories

- Ability to lead a project

- Ability to build good relationships, interact with others and effectively work together to achieve a common objective

- Ability to understand and taking turns for the role of leadership and members

- Ability to recognize and respect others characters, behaviours and belief

\section{S4: Information management and lifelong learning skills:}

- Ability to find and manage information from different and diverse sources 
- Ability to accept new ideas and capability of autonomous learning

S5: Management and Entrepreneurship skills:

- Ability to identify business opportunities

- Ability to sketch business plan

\section{S6: Values, Attitudes, Ethics and Professionalism:}

- Ability to understand economic, environmental and socio-culture impact in professional practice

- Ability to analyse and make decisions in solving ethical problems

\section{S7: Creative and Innovative skills:}

- Ability to come out with new or unique ideas, mechanism, projects or proposals

\section{S8: Social skills and sense of responsibility:}

- Initiatives to reach out to the community and society as a whole

- Ability to identify social duties and interact appropriately with others

\section{Follow-up questions:}

1) Are UKM's students marketable in terms of:

- Globally? Why?

- Locally? Why?

2) What is the most important skill or element that ensures the marketability of UKM's students based on the current market's demand?

3) What are some of the factors that greatly reduce the marketability of UKM's students?

4) What are the significance or benefits in ensuring that UKM's students are marketable in terms of:

- Student's aspect?

- Societal aspect?

- University's aspect?

5) What are the possible harms if UKM's students are not marketable in terms of:

- Student's aspect?

- Societal aspect?

- University's aspect?

6) What are the initiatives of your faculty/campus/college/organization in order to further enhance the development of the 8 dimension of soft skills outlined by UKM?

7) What are some of your suggestions to further elevate the marketability of UKM's students?

\section{Results \& Discussion}

Perceptions from 60 respondents were studied via face-to-face interview. The perceptions comprises of 35 final year students, 2 lecturers, 3 Private Sector representative and 20 first year students. The first and final year undergraduate students came from Faculty of Dentistry $(n=8)$, Faculty of Medicine $(n=5)$, Faculty of Health Science $(n=12)$, Faculty of Pharmacy $(n=5)$ and Faculty of Law $(n=5)$. The two lecturers were from the Faculty of Medicine and the Faculty of Health Science. 10 of the first year students were from the Faculty of Medicine, 5 from the Faculty of Dentistry and the other 5 from the Faculty of Health Science (Table 1). 
Table 1. Demographic profile of the respondents

\begin{tabular}{|ll|}
\hline Variables & Frequency (n) \\
\hline Age cohorts & 20 \\
21 and below & 30 \\
Above 21years & \\
\hline Education background & 20 \\
First Year & - \\
Second Year & 35 \\
Third Year & 5 \\
Professional & 5 \\
\hline Faculty & 5 \\
Medicine & 5 \\
Pharmacy & 8 \\
Dentistry & 12 \\
Health Sciences & 5 \\
Law & \\
\hline
\end{tabular}

The summary of the interviews is outlined as below:

\subsection{Global vs Local}

57 out of $60(95 \%)$ of respondents agreed that UKM's students have their places in the local workforce especially in the health sector. However, the number of graduates has decreased when it comes to other sectors. This most probably because there are insufficient amount of graduates were able to be tracked who probably working internationally. There are few of UKM's graduates who have successfully established themselves exceptionally well in the global arena and most of them have marked the milestone of global establishment among UKM's graduates.

\subsection{Communication skill wins}

Most of the respondents $(\mathrm{n}=57)$ agreed that communication skills contribute to the most weightage in determining the marketability of UKM graduates. Only 3 respondents stated that entrepreneurial skill is as equally important as communication skills. They claimed that the complementary effect of both skills will maximize the marketability of graduates even better than just having exceptional communication skills. There are several levels of analysis on why communication skills became the utmost important skill. According to $95 \%$ of both first year and final year undergraduates cohorts, having a good communication skill will allow graduates to be more influential when selling ideas, as it will get people listening. 2 of respondents, who are lecturers, also shared their opinion as having a good communication skill enables them to become good lecturers as they are able to cater for the understanding of student better. This indirectly sparks motivation in students as they can comprehend the matter easier. 3 respondents from the private sector stated that people with good communications skills are crucially needed especially in the pharmaceutical industries because on the first level, pharmacists do not only need to understand profile of different drugs, but they also need to be able to deliver the drug information to customers in a layman's term. On the second level, pharmacists who ended up in the legislation and regulation sectors requires even better communication skills as they need to be firm and clear when it comes to presenting reasons on why some drugs are not allowed to penetrate the market.

With all of the examples provided by the respondents, communication skills top the findings among other soft skills because a good communication skill portrays how to get the right message across from one individual to another. Hence, it exists in any situation which includes getting agreement in mutual partnership, promoting health, advocating legislation, nurturing through education and conveying information through social media.

However, there are many challenges in performing a good communication skill. Respondents have listed their concerns in most of the recent UKM graduates: 
1) Poor mastery of the both Bahasa Malaysia and the English language.

Fluency in conversing Bahasa Malaysia with formality has been found lack in recent graduates during job interviews. This is greatly caused by the frequent usage of colloquial language in every day conversation. Thus, when it comes to formality, majority of UKM graduates tend to mix the language with English. Furthermore, majority of respondents also agreed that poor mastery of the English language greatly reduces their communication skills. Firstly, such a problem will restrict the ability to speak fluently in English and considering this language as a second language in Malaysia, failure to deliver information during job interview will not benefit themselves thus cause to lose job opportunity to other graduates. It also creates a sense of inferiority complex where UKM graduates will feel that they are not as good as their rivals in the interview. Not being able to speak fluently and the presence of inferiority will greatly reduce confidence level in the students. Confidence is greatly required when it comes to speaking out the ideas as it allows discussion to go on with different people. Lastly, poor mastery of the English language not only limits the output capacity but also the input as well. This is because poor mastery makes it difficult for someone to understand new things, issues, terms and to keep up with technology.

2) Lack of confidence

Lack of confidence can be caused from various factors. This may include lack of persuasive skills, poor mastery in the language, doubts and also lack of content to present. However, it is something that can be easily improved by reading and keeping up to date with current issues. Confidence is a prerequisite before you can start communicating and break the ice, be it from making new friends to sealing a contract. Confidence gives the courage to speak out or initiate a conversation and therefore without it, some good ideas may not be heard in a discussion.

3) Speaking styles

This attribute is largely seen when students are unable to identify their audience while communicating. For example, a doctor should be using a layman's term to explain coughing symptoms to a layman patient, not by mentioning heavy medical jargons. Otherwise, the symptoms cannot be delivered to the patients informatively.

4) Communication in the new era

Nowadays, communication skills have been transformed to be an important tool to connect each other in the workplace and public life. By integrating digital technologies in business and everyday life, this skill is the top notch of desired skill looked by the employers in recruiting young graduates. The Partnership for 21st Century Skills (P21, 2009) has proposed five sets of communication skills. These include:

1) the ability to articulate thoughts and ideas effectively, both orally and nonverbally,

2) the ability to listen and make sense of what is being said,

3) the ability to utilise communication effectively,

4) the ability to utilise a wide range of media and related technologies,

5) the ability to communicate in different environments.

Therefore, UKM graduates has to know how to keep up with the technology and communication skills not only can be evaluated in a face-to-face interaction, it is extended to another level, by using different software and Web tools whilst sharing ideas in a virtual environment.

\subsection{Significance of marketability of UKM graduates and the possible harm without it}

By improving students' marketability, UKM graduates will gain more benefits; as they get to enjoy includes to have social mobility, wider avenue to speak their minds and opportunity to explore their capability in socializing, gain more influence to be known, and later to become a leader in an organization. If they fail to become marketable, their chances to be employed become limited and once they have been recruited in an organization, they could not proceed further in their career. With more educated and competent graduates working in various departments and administration, the overall standards of living of the society will be elevated. If more mediocre graduates are in society, not only that it will add up to the cost of consumption resources, their returns to the nation are hardly beneficial for the greater good and may just become unemployed which ultimately harms the economy.

\subsection{How can UKM help?}

Within UKM, various departments have different initiatives introduced to further polish and enhance the soft skills dimensions of their students. According to the Faculty of Medicine at UKM, their curriculum includes "Problem-Based Learning", "Meet the Expert" and "Personal and Professional Development" sessions. Each session 
focuses in developing the ability of students to present their research evidently and persuasively, provoke positive inquisition, culture the habit of asking good questions to the experts, organize projects that includes reaching out to the community and Non-Government Organizations (NGO). This is to inculcate good moral attributes and generate resourceful, viable and multi-talented doctors that work beyond the wall of offices and hospitals. In contrary, the Faculty of Law will hold a presidential speech when it comes to election week. This signifies a very professional act of students, attempting to create a healthy competition with a great sense of leadership and responsibility.

On behalf of the residential college, the initiatives start by providing facilities for students to organize their community projects, assigning an advisor to each project and establish a student council to monitor each progress until the end. This establishment is a medium to scout for talented future leader that possesses exceptional persuasive skills and leadership skills. A respondent who is also a representative from the Student's Council explained that programs must always have a society-university collaboration to ensure that there's a reach out as a part of student's social responsibility. The program must also incorporate all the dimensions of soft skills to ensure frequent exposure that soon, will become integrated in the students' life. However, these programs must be presented to the Student's council first to ensure the quality of each program before it can be initiated.

\section{Conclusion and Suggestion}

University Kebangsaan Malaysia will have a better image national and internationally if their students are able to communicate well with society. Therefore, there is a need to reflect the curriculum standards. Only currently, UKM has proposed a curriculum that involves the mixture of different faculties so students from various backgrounds can share their knowledge and how they've been taught in their respective subject. It would have been better if more of these programs put forward great attention or emphasis towards communication skills to improve the overall development of UKM students. Lecturers too, will be mobilized from one faculty to another, as an effort to learn a new teaching-learning method so it can be introduced back to their faculty. As quoted in Roselina, 2009;

"Institutes of Higher Learning must create awareness to graduates on the needs and expectation of the globalized job market. The effort should be a joint effort between the students, lecturers, Faculties, Colleges of Residence, and Universities. More importantly, students must be made to realize the importance of enhancing their soft skills so that they are able to compete in the world without boundaries. While suggestions on infusing soft skills have been deliberated by the Institute of Higher Learning, the evaluation of these elements is left to the academics."

This article has successfully identified the key soft skills that greatly affect student's marketability in society which is communication skills. Communication skills are suggested to be more holistic compared to other skills and gives greater benefit.

\section{Acknowledgements}

We would like to express our greatest gratitude to the 3 private sector representatives for contributing their insights and views regarding the demanded skills of graduates. We also would like to thank lecturers from the Faculty of Medicine and the Faculty of Health Science, final and first year undergraduate medical, dental, pharmacy and health science students for making up the majority of respondents and for contributing their opinions and suggestions. This study was funded under grant PTS-2013-133 and was approved by the Secretariat of Medical Research and Innovation, Universiti Kebangsaan Malaysia (FF-2014-260).

\section{References}

Ashton, F. (1994). The other managers' competencies. Training Officer, 30(1), 15-16.

Caudron, S. (1999). The hard case for soft skills. Workforce, 78(7), 60-64.

Columnist. (2013) Helping unemployed graduates in Malaysia. New Straits Times. 14 March 2013. Retrieved from $\mathrm{http} / /$ www.nst.com.my/opinion/columnist/helping-unemployed-graduates-in-malaysia-1.234315 Retrieved on 10th September 2014.

Hon, L., \& Grunig, J. E. (1999). Guidelines for measuring relationships in public relations. Institute for public relations commission on PR measurement and evaluation, University of Florida.

Hopkins,G. W. (2000). Qualitative research design. Sportscience 4 (1). http://sportsci.org/jour/0001/wghdesign.html. Retrieved on 10th September 2014.

Ishak Yussof, Rahmah Ismail \& Rubiah Sidin (2008). Graduates and Job Market: Case of UKM Graduates. Jurnal Akademika, 72:3-24. 
Ismail, N.A. (2011). Graduates' characteristics and unemployment: A study among Malaysian graduates. International Journal of Business and Social Sciences, 2(16), 94-102.

Kee, C.P., Ahmad, F., Ibrahim, F., \& Nie, K.S. (2012). Correlating graduate marketability dimensions with measurements of University-student relationship. Asian Social Sciences, 8(6), 63-73.

Kemper, C. L. (1999). EQ vs. IQ. Communication World, 16(9), 15-19.

McMurchie, L. L. (1998). Careers can rise or fall with EQ. Computing Canada, 1(9), 1821.

Mason, M (2010). Sample Size and Saturation in PhD Studies Using Qualitative Interviews. Forum Qualitative Sozialforschung / Forum: Qualitative Social Research, [S.l.], (11) 3. Retrieved from http://www.qualitative-research.net/index.php/fqs/article/view/1428/3027. Date accessed: 14 Sep. 2014.

Ministry of Higher Education (2010). Laporan Kajian Pengesanan Graduan (translation: Graduates Tracer Study Report) 2010, Kuala Lumpur: Ministry of Higher Education Malaysia.

P 21. (2014). Learning for the 21st century: A Report and MILE Guide for 21st century skills. Retrieved from http://www.21stcenturyskills.org on $11^{\text {th }}$ September 2014

Roselina S. (2009). Soft skills at the Malaysian institutes of higher learning. Asia Pacific Educ Rev 10:309-315. http://dx.doi.org/10.1007/s12564-009-9038-8

Schulz, B. (2008). The Importance of soft skills: Education beyond academic knowledge. Journal of Language and Communication, June 2008, 146-154.

Shaharuddin Ahmad, Noraziah Ali \& Mohd Fauzi Hamzah (2011). UKM Graduate Employability: A Comparative Study Between Science and Non-science Disciplines.

Spencer, L. M., \& Spencer, S. M. (1993). Competence at work. New York: Wiley. Jurnal Personalia Pelajar, Bil 14 : $81-90$.

UKM Alumni Relations Office (2011). Laporan Pengesanan Graduan (translation: Graduates Tracer Study Report) UKM 2011, Bangi: UKM Alumni Relations Office.

UKM Alumni Relations Office (2012). Laporan Pengesanan Graduan (translation: Graduates Tracer Study Report) UKM 2012, Bangi: UKM Alumni Relations Office.

UKM Alumni Relations Office (2012). Laporan Pengesanan Graduan (translation: Graduates Tracer Study Report) UKM 2012, Bangi: UKM Alumni Relations Office. 